moreover, that the presence of the vinegar-plant will give rise to the formation of acetic acid in a saccharine solution, rise to the formation of acerature than that at which the change could take place, were the acetic ferment absent.

There is, however, one remarkable difference between the mode of action of the alcoholic and acetic ferments. As the process of alcoholic fermentation consists of interchange of process of alcoholic fermentation of carbonic acid from the fluid undergoing the change, the yeast torula seems to be in active vegetation as truly throughout the whole fluid, even at the bottom; its greater collection at the surface being simply due to its being carried upwards by the escaping gas. The vinegar-plaut, thallus, or ferment, on the other hand, is active only on the surface of the fluid. Old plants once submerged-at least in the saccharine solutions used in the making of vinegar which had a sp. gr. 1·040do not rise again, but continue without change or increase at the bottom of the fluid, whilst a new plant forms on the surface. How far that surface growth of the plant may be connected with the absorption of the oxygen necessary for the acetifying process, it is, at present at least, impossible to say.

It may be asked, how comes the vinegar thallus in a solution to which no spore or spawn from another plant had been added? It is, I believe, a fungoid development, the form of which is determined by the nature of the medium in which it vegetates; but when it is developed, I believe it is capable of assisting in, and predisposing to those elementary changes and interchanges which take place in the acetous fermentation, and perhaps of aiding the absorption of oxygen necessary for the process. With such a view, the originating spores may have been those of the sugar fungus, or of some of the common moulds. Indeed, if vinegar with a growing vinegar-plant on its surface be exposed to the atmosphere for a considerable length of time, the vinegar thallus passes into a crop of mould. Dr. Carpenter* observes, " of all the protophytes it may be remarked, that the conditions under which they are developed, produce a considerable modification in their mode of growth, and may even effect such a change as to obscure their characteristic "nisus"". The history of the vinegar-plant appears to corroborate this idea. Throughout this paper, the vinegar thallus has been spoken of as a fungus; and if it be characteristic of the fungi that they are most readily and perfectly developed in situations where azotized matter in a state of decay or change furnishes them with a free supply of carbonic acid and anmonia, then must the vinegar plant belong to them, for we have seen that in the solution of refined sugar from which azotized ammonia-yielding clements had been removed by purification, little, if any, development took place, and the acetification was weak. This latter fact, moreover, proves that the catalytic action is dependent upon the growth of the thallus; for were it not so, were it simply occasioned by the presence of a thallus, there is no reason why the acetification of the pure sugar solution should not have advanced equally with that in the unpurified solutions, each having a similar old plant introduced into them. Again, the vinegar thallus developed on the surface of the saccharine fluid must, necessarily, have continued fresh supplies of whatever element is most essential to its development from the free communication between the particles of the fluid, and as long as the fluid can furnish the element or clements, it continues to flourish; if, however, as stated above, the growth of the thallus be permitted to continue upon a portion of vinegar exposed to the atmosphere for a considerable time, probably from exhaustion of the element required, the vinegar plant degenerates into simple mucar. Similarly, mucar or mould forms on the surface of a solid mass of cheese or of sugar preserve. There can be no interchange of particles as in the fluid, consequently the outer layers of the supporting medium can only furnish the food for growth. Is it that the vinegar thallus requires a more ample supply of some particular element of saccharine and at the same time azote-yielding fluids or sub- stances, for its development than is requirite to support the growth of the moulds?

The observations in the foregoing paper I offer rather as suggestive than otherwise. The subject is one which does not appear to have undergone any special investigation, and my chief object is to direct to it the attention of those who have more leisure than myself to devote to such inquiries.

Haunton, Burton-on-Trent, Auguet 25th, 1855.

\section{CLINICAL ILLUSTRATIONS OF SOME DISEASES OF THE OESOPHAGUS.}

\author{
By C. E. REEVES, B.A., M.D. \\ [Continued from page 704.] \\ SPASMODIC STRICTURE.
}

Stricture from Afpection of the Stomach. Case 1 . Mr. Abernethy relates the following case.* A lady had for many years suffered from what her medical attendant supmased to be organic stricture of the csophagus. She was posed reduced to such a state, that food could be taken only in very small quantities at a time, large quantities of liquid being necessary to enable it to descend into the stomach. He was requested to pass a bougie, but he declined to do so, as the disordered stomach, furred tongue, and tender epiastrium, led him to suppose that it was only sympathetic. Attention to the stomach and bowels soon gave relief to the difficulty in swallowing, and she ultimately got quite well.

CASE II. A young man, $t$ of florid complexion and full habit of body, after walking a considerable distance on a very hot day, was suddenly taken with severe pain at the orifice of the stomach, with great difficulty in breathing, and inability to swallow. He was cured by copious extraction of blood. In the following winter, a slight return, which yielded to purgatives. In the following spring, he was suddenly awakened early one morning with the pain and other symptoms. Bleeding gave him grcat relief, but only for a short time. He was again bled, by which he was permanently relieved. CASE III. A female, aged 69, $\neq$ had suffered frequently from pains in the throat, descending at times down to the stomach, with great difficulty in swallowing. A bougie met with some slight obstruction at the lower part of the pharyns, but gave great relief to the obstruction. Five days afterwards, a pain seized her at the cpigastrium, and obstruction for the first time manifested itself at the entrance into the stomach. She sank soon after. The stomach was thickened throughout, except for one or two inches near the pylorus, throughout, would not contain more than six ounces of fluid.

CAse IV. A man, aged 45, was, says Monro, $\S$ under the

care of my father, Dr. Kcith, Mr. Wardrop, and Mr. G. Bell; he had been suffering from dyspepsia and pain in the stomach for two years, and for the last thrce months from occasional attacks of spasmodic stricture. In October 1810, the stricture became more troublesome, particularly at breakfast. On October 17, a bougie was passed, an obstruction being felt quite distinctly; but it was not relieved until the 9th of November. A cold reproduced the dysphagia, which yielded in the course of a few days to the introduction of the probang. He sank the following May, with all the symptoms of malignant disease of the stomach. The œsophagus was found quite healthy, the stomach distended with dark coloured fluid, and adhering to the liver, a fungous ulcer existing at this point.

Stricture from Affections of tie Liver. Portal (Maladies du Foie) mentions a case of hepatitis, attended by another physician and himself, where stricture of the csophagus existed.

Frank met with it in a case of inflammation of the superior surface of the liver. He also mentions a case which

- Abernethy's Surgical Works, vol. i.

+ 1)r. Innes, Medical Communications.

Monro, Horbid Anatomy of the Stomach and Gullet. 
occurred to an Italian physician, where it depended on a worm in the cystic duct.

Mayo (Outlines of Pathology) mentions an instance of its occurring in a female, who was suffering from inflammation of the surface of the liver.

Stokes, in his Clinical Lectures, ${ }^{*}$ mentions having met with it in several instances during an epidemic gastroenteritis accompanied by hepatitis.

Case. The Marquis of T.,t after suffering some time from disease of the liver, had an abscess in the right side, which burst, allowing the escape of pus and a great number of gall-stones. It then healed, but four other abscesses occurred in the next ten years. Six months before death, great difficulty in deglutition came on, for which leeches and blisters were applied, with but temporary relief. $\mathrm{He}$ at last sank from diarrhœa. The cesophagus was quite healthy, but the liver was reduced to half its usual size, and adhered to the diaphragm by cellular bands. The gall-bladder was wanting, its place being supplied by a little fibrous substance, in which ended the cystic duct.

Stricture frod Affections of the Diaphragu and the Pericardiom. Case. A female, aged $32,+$ began to suffer from difficulty in swallowing, with a constant sensation of constriction in the throat, and pain at the lower part of the sternum, accompanied by intense agony in laughing. The slightest sudden motion brought on an attack of the agony at the epigastrium. Warm baths, with opiate frictions and hemlock poultices, gave relief. She was ultimately cured by blisters to the epigastrium, and leeches to the anus.

Heister (Obs. Med. Mis. Obs. 15) reports an instance of a man suffering from inflammation of the diaphragm, who had spasmodic contraction.

In the following case, reported by Portal (Mém. sur plus. Maladies) the pericardium was affected. The mother of Dr. $S$. was taken with severe pain in the larynx and pharynx, affecting speech, respiration, and swallowing, particularly of fluids, which returned by the nostrils. Fever, with hard quick pulse, also existed. She sank on the serenth day. The larynx and osophagus, to their great surprise, were quite healthy, but the pericardium was thickened of a dark violet hue, and adherent to the heart, which was also softened.

Stricture fron Affections of the Uterus. Riedlin reports the case of a female who, at the fourth month of pregnancy, became subject to spasmodic contraction of the cesophagus, so that she was able to swallow only a little broth. Immediately after her confinement, it began to diminish, and at the end of a month she could swallow with the greatest ease.

In the Ancien Journat, the case of a woman is published, who suffered from this affection in eleven successive pregnancies. (Leblond, Thèse de Paris, 1822. No. 196.)

Villeneuve relates an instance of a female suffering from uterine disease, who had constant constriction of the throat. Pattissier at the same time mentions a like instance. A seton was introduced into the neck, but to no purpose. In neither of the cases was there hysteria. $\$$

Mondiere $\|$ met with it in a case of menorrhagia. In this case, it is doubtful whether it might not have depended on the loss of blood, and not on any uterine irritation. Sir B. Brodie, in his work on nervous affections, publishes the case of a lady who had suffered three years from spasmodic stricture, the result of repeated discharges of blood from piles. Her face was blanched, she could not swallow solids, and even fluids with much difficulty. A probang was passed with the greatest ease. By tonics and cold injections, she was, at the end of four months, able to swallow with ease.

Rechelmi $\pi$ reports the following case. A. F., aged 39, nervous, confined forty days. She had been much weakened by several csuses, particularly by excessive menorrhagia. Soon after her labour, a sudden mental shock took away her

- London Medical Journal, 1894.

+ Nacquart, Jour. Gén. de Med., tome lrox.

- Dumas, Consult. Médicales, 628.

Bibliothèque Médicale, tome zlvii

II Archives Gén. de Med., 1893.

T Bibliothèque Médicale, tome xlvii. consciousness for some time. On recovery, she complained of painful constriction of the pharynx, food and liquid being immediately rejected. It was much worse during the daj immediately rejected. It was much worse during the datended with difficult respiration and palpitation of the heart. There was extreme emaciation. Great mental depression always preceded the dysphagia. Giving milk to the child always induced an attack. By cold bathing, and amusing her mind, she became, after suffering ten months from it, much better.

A young female,* brought up in the country, and accustomed to an active life, came to live in town to attend on an invalid. She first began to suffer from headache, loss of appetite, and constipation, followed by romiting of all taken, and considerable emaciation. In a short time, she complained of pain in the throat, behind the cricoid cartilage; the attempt to swallow food produced constriction, followed by its immediate rejection. A common catheter was passed, with immediate relief to the dysphagia and romiting. Medicines were given, but with little benefit to the hysteria and indigestion. The romiting and dysphagia soon returned, although less severe. The catheter was again passed, with the same benefit as before. She was sent back into the country, and was soon quite well.

A chlorotic and hysterical female, aged $25,+$ in whom the menstrual discharge had been scanty for ten years, each epoch being attended with difficult breathing, during the last five years she had suffered from dysphagia. Food, when swallowed, was immediately rejected, and severe pain was excited throughout the whole length of the œsophagus. In the winter, the attacks would come on suddenly in the night, continue longer, and be more severe than at any other time; the tongue and uvula becoming affected, and at the same time frequent hiccough. Throughout the attack, a constant pain, of a spasmodic character, existed at the præcordia, which rendered the breathing difficult.

In the case published by Dr. Tilt, in his valuable work on Diseases of Women, $\neq$ the person, aged 27 , menstruated at thirteen, scantily and irregularly; at fourteen, it was attended with severe pain. She married at twenty-four, and had a child, which she could not suckle: the menstrual discharge reappeared at the end of threc months. In the winter of 1851 , she was taken with cough and pain in the pit of the stomach; and food seemed to meet with an obstruction just above the præcordia. She was awoke on the fourth night of the attack, suffering from severe suffocative pain in the epigastrium. There was no fever. She had leucorrhœa, and the menstrual discharge was soon expected. The apnlication of hot water gave relief. Sedatives were also given, and plasters of the same character applied to the epigastrium and the region of the ovaries. The pain, however, returned at intervals, rendering the frequent exhibition of morphia necessary. The menstrual discharge did not come on for three weeks. At the next period, she had colic, with pseudo-narcotism, followed by violent epigastric pain, which shifted to the spine, and passed down to the sacrum, then the menstrual discharge appeared. Since this time, she has been subject to spasmodic contraction of the osophagus during meals. The food is suddenly arrested,-sometimes for a time only; at others, the whole dinner is brought up; but generally only the food, or a little ropy mucus,-after which she is enabled to eat a hearty meal.

In the case published by Percival.| A young lady, aged 13, had suffered, when seen, six weeks without any intermission from dysphagia. She had had dysphagia before, but it had left her for a month. Solids passed down to the orifice of the stomach, and were then rejected with a convulsive effort. Warm fluids, swallowed by sipping, met with no resistance; otherwise they were rejected. In the evening the spasm relaxed, leaving a sense of uneasiness at the pit of the

* Cummin, Edin. Med. Chir. Transact, vol. iii.

+ Zimmerman, Acta Helvitica, lib. II.

- Second edition, page 64

Dr. Tilt has had the kindness to inform me that she still continues in the same state.

II Transactions of the College of Physic, vol. ii. 
tomach. She had menstruated scantily at nine, but only trice since. Feet very cold, and bowels constipated. By the application of a galbanum plaster to the throst, milk diet, and exercise, cured.

Bright* mentions the case of a female brought into Guy's Hospital, suffering from stricture of several weeks' duration. The introduction of a probang brought on a fit of hysteria.

Stricture from Gout. A cise fell under my notice a short time back, where a person, while suffering from an attack of gouty spasm of the stomach, everything was rejected the moment it reached the lower part of the pharynx.

Mr. Watson (quoted by IIowship) speaks of a case occurring in a gouty gentleman.

Courant describes a case where it preceded the paroxysin of gout.

Stricture froy Scppiession of Cctayeods Eruptions. Manclerc, + a casc in a nervous fenale, where the suppression of an eruption on the biack of the hand, by an astringent application, was followerl ly vomiting and spasmodic constriction of the throat.

Aird mentions the casc of his son, aged 18, in whom the sudden disappcarance of a chronic cruption was followed by swelling and pain in the umbilical and hypochondriac regions, and spasm of the resophagus.

Stricture from Afrections of the Mind. An instance is recorded in one of the old writers, of a man who could not swallow a consecrated wafer. Another case is also mentioned, of a monk who never could swallow a particular kind of fluid, some of which liad once found its way into the trachea.

Boyer mentions an instance of a female, who, having once had a piece of chicken arrested in the throat, never after could swallow any without its inducing spasm.

I am acquainted with an individual who cannot take a very small new potato, from a surfeit in early life. The moment one is introlucel into the mouth, a sense of constriction is produced; and if he attempts to swallow it, it is rejected.

Percival relates an instance where swallowing a pea excited spasms of five or six (lays' duration in an elderly lady.

Duchateau ('lome 79 of Jour. (ién. de Méd.) has published the case of a nervous female, who fancied that she had swallowed a pin. She was at last cured by an enema, and then showing her a pin, telling her it had been discharged from the bowel.

Mondiere (Arch. Gén. de Méd. 1४33) cites the following cases:

A man, the subject of hypochondriasis, after being bitten by a dog, touk to his bed, and had difticulty in swallowing for fifteen days. But on Ferrier telling him that persons suffering from hydrophobia died on the eighth day, he got up and went about his usual occupations.

Barthelemi, the professor at $\Lambda$ lfort, was bitten by a little

dog. He believed that he was suffering from hydrophobia. For three days he was unable to swallow; the sight of water affecting him like electrical shocks.

Barbatini mentions an instance where a man, while out hunting, was bitten by his dog. The dog did not return home with him. Three days passed: the idea then took possession of him that he was hydrophobic. He had soon all the symptoms, even to occasional attacks of furor. On the ninth day the $\log$ returned, well and playful. From that moment he hecame quite well.

A man had been absent from heme for twenty years. On his return, he learnt that his brother had died of hydrophobia, from the bite of a dog which had also bitten himself. Ile was immediately seized with all the symptoms of the disease, and sank under it.

In flaymation of the U PPER part of the Spival Cord. Hoffuan mentions an instance where spasm of the cesophagus existed in a case of inflammation of the upper part of the cord.

Harringten Siquare, London, July lisis.

- liepurts of Medical Cases, vol. ii.

+ Jour. Gén. de Méd., tome xxii.

\section{TURPENTINE IN THE TREATMENT OF PURPURA.}

By WM. SMITH, Surgeon, Fellow of the Royal Medical and Chirurgical Society of London, etc.

In the Association Jodrsal for June 27th, is a review of Dr. Neligan's work "On Diseases of the Skin"; and some remarks on the treatment of purpura by oil of turpentine.

Having recently had under my care two serere cases of this disease, and having treated each of them differently, I trust a comparative view of the remedial effects of the medicines employed will not be uninteresting. I must premise that my attention was drawn to the use of oil of turpentine by Dr. Copland's recommendation of it in the article ont his disease in his Dictionary. The mode, however, in which I administered it, was advised by a gentleman of great practical experience in the treatment of disease, now retired from the profession, and who informed me that he had always found it successful in cases uncomplicated with organic disease.

The cases (which I purposely report very briefly), are as follows:-

F. $\mathbf{W}$, aged 6 , residing at Bolsover, Derbyshire, was attacked with large spots of purpura, principally on the lower extremities in the autumn of 1852 . Her mother employed domestic and other remedies till the spring of 1853, when, the child becoming much worse, she called me in.

The patient was a very fine though somewhat plethoric child, with ruddy sanguine complexion, and with all the external appearances of mide health. The locality in which she resides is one of the highest and driest in England, and distinguished generally by the longevity of its inhabitants. About six-serenths of the cases which fall under my care are, however, of the zymotic class. The drainage is bad, and many of the wells have been poisoned by the leakage of the cesspools. During the spring and summer of 1852, malignant scarlatina prevailed to in immense extent, and during this and last year furunculoid eruptions and erysipelas have been common and severe.

In the case now narrated, the child had for some time lived chictly on animal food, in fact, on the usual farm house diet-bacon. On my first examination of her, March 15 th, 1853, several very large ecchymoses were present on the legs, and one of the size of an egg on the forehead, the result of a slight blow. The smallest pressure produced them. There had been considerable bleeding from the nose on several occasions, and once from the bowels. There was oozing of blood from the gums. The urine was high coloured, and the alvine eracuations pale and generally constipated. I treated this case first with purgatives, and then with diluted sulphuric acid. She was also ordered to suck oranges, drink lemonade or very weak beer, and to eat rhubarb tarts.

The case did not progress with this treatment; the epistaxis was, indeed, somewhat diminished, but the other symptoms continued much the same.

Under these circumstances I gave the child citrate of iron combined with citric acid. This succeeded better, and after three months perseverance, the cutaneous discolorations ceased. The progress of cure was, however, extremely slow, and a relapse has since occurred, but the patient has again recovered under the use of the citrate of iron.

The second case occurred in a little girl, aged 4, generally strong and active, and residing in a spacious house situated near a tannery. This case was very acute. There was first remarked in her a disinclination to food, especially regetable; and extreme irritability of temper. The bowels were extremely constipated. These symptoms ushered in the attack. The lower extremities became weary and stiff towards evening, and three large elevated spots, varying from the size of a fourpenny piece to that of half-a-crown appeared upon them. These spots became rapidly purple and soft, and gave the impression to the touch of fluid blood under the skin. In the morning they became yellow, and gradually were absorbed, but others, larger and higher up 